\title{
Análise da percepção dos gestores e empregados acerca do comportamento inovador em uma indústria automobilística
}

\section{Analysis of the Perception of Managers and Employees about Innovative Behavior in the Automobile Industry}

\author{
Cristiana Fernandes De Muylder ${ }^{1}$ \\ Orcid: https://orcid.org/0000-0002-0813-0999 \\ Jefferson Lopes La Falce ${ }^{3}$ \\ Orcid: https://orcid.org/0000-0002-3293-2908
}

\author{
Liliane Andrade Araújo ${ }^{2}$ \\ Orcid: https://orcid.org/ 0000-0003-2297-8379 \\ Sander Rosa de Laia Mesquita ${ }^{4}$ \\ Orcid: https://orcid.org/0000-0003-4644-649X
}

\begin{abstract}
Resumo
O artigo tem como objetivo analisar o comportamento inovador sob as dimensões apresentadas no estudo de De Jong e Den Hartog (2010) pela ótica do gestor e do empregado no setor industrial do estado de Minas Gerais. Para o estudo da percepção do empregado, utilizaram-se como instrumento de pesquisa os estudos realizados por Scott e Bruce (1994) e Janssen (2000). Trata-se de uma pesquisa descritiva com uma metodologia quantitativa, realizada por meio de uma SurveyMonkey, nos períodos de novembro de 2016 e maio de 2017. Percebeu-se uma motivação expressiva dos gestores para instigar o comportamento inovador nos funcionários, porém esta foi pouco percebida sob a ótica dos empregados, o que corrobora os resultados da academia segundo os quais os gestores e empregados necessitam convergir para o desenvolvimento organizacional, dessa forma a empresa terá oportunidades de se destacar no setor de atuação.
\end{abstract}

Palavras-chave: inovação; comportamento inovador; setor automobilístico.

\begin{abstract}
The article aims to analyze the innovative behavior under the dimensions presented in De Jong and Den Hartog's (2010) study from the manager and employee perspective in Minas Gerais' industrial sector. The study of the employee's perception was used to research the studies carried out by Scott and Ruce (1994) and Janssen (2000). It is descriptive research with a quantitative methodology, carried out through SurveyMonkey between November 2016 and May 2017. It was noticed a significant motivation of the managers to prompt the innovative behavior in the employees. However, little was perceived from the employees' perspective, corroborating with the academy results in which the managers and employees need to converge for the organizational development. In this way, the company will have opportunities to excel in the industry.
\end{abstract}

Keywords: innovation; innovative behavior; automotive industry.

\footnotetext{
${ }^{1}$ Universidade FUMEC / PDMA. Belo Horizonte (MG), Brasil. E-mail: cristiana.muylder@fumec.br

${ }^{2}$ Universidade FUMEC. Belo Horizonte (MG), Brasil. E-mail: liliaraujo00@outlook.com

${ }^{3}$ Universidade FUMEC / PDMA e Fundação Dom Cabral. Belo Horizonte (MG), Brasil. E-mail:

jefferson.la.falce@gmail.com

${ }^{4}$ Universidade FUMEC e Fiat Automóveis.. Belo Horizonte (MG), Brasil. E-mail:

sander.mesquita50@gmail.com
} 


\section{INTRODUÇÃO}

A Revolução Industrial do século XIX marcou a transformação dos serviços prestados nas fábricas da época, passandose da produção artesanal para os serviços industriais, um grande desafio para os produtores da época em que ocorreu a disrupção da forma pela qual se produziam os produtos comercializados. Esse marco mostrou a inovação como diferencial para a vantagem competitiva entre as organizações, segundo Prajogo e Ahmede (2006).

A indústria vem passando por transformações cada dia mais impactantes; atualmente, vive-se a $4^{\circ}$ Revolução Industrial, identificada pelo termo "Indústria 4.0". Conforme Vaidyaa, Ambadb e Bhosle (2018), essa fase é definida como o mais novo nível de uma organização e responsável por controlar toda a cadeia de valor e o ciclo de vida dos produtos, utilizando uma abordagem mais individualizada.

Segundo Prajogo e Ahmede (2006), introduzir o conceito de inovação em uma organização requer análise do mercado em que ela está inserida, medindo-se quão maduro ele está para determinar qual estratégia de inovação implantar. A capacidade de desenvolvimento de novos produtos ou serviços deve acompanhar as alterações de mercado e, principalmente, considerar as expectativas do cliente e seu comportamento como consumidor.

Além das bases que compõem uma gestão, considera-se subjacente a parte humana, como princípio básico da inovação de sucesso (PRAJOGO; AHMEDE, 2006). A criatividade tem associação direta com o termo inovação, refere-se diretamente ao incremento e à prática de novas ideias, portanto as organizações, a cada dia, buscam no mercado profissionais que apresentam tais características (CLAPHAM, 2003). As empresas compreendem que o profissional com comportamento inovador contribuirá para que a organização garanta a vantagem competitiva no mercado. O comportamento inovador de determinado indivíduo, ao multiplicar-se, estende suas benfeitorias e inovações a todos os envolvidos na organização (DAN et al., 2018).

Diante do cenário apresentado, em que o comportamento inovador está diretamente relacionado ao profissional criativo, que contribuirá com a empresa, trabalhando para a geração de inovação e ganhos de vantagem competitiva diante dos concorrentes, surge a seguinte pergunta deste trabalho: Como são percebidas, por gestores e colaboradores, as características do comportamento inovador dentro de uma indústria do setor automobilístico situada no estado de Minas Gerais?

A organização pesquisada está situada no estado de Minas Gerais, sendo que o grupo pesquisado tem unidades produtivas em 40 (quarenta) países e presença comercial em aproximadamente 150 (cento e cinquenta). Apresenta um market-share (participação no mercado) expressivo, conquistando a liderança no segmento de veículos leves. Possui cerca de 40 (quarenta) mil colaboradores, e é produzida uma média anual de 800 (oitocentos) mil veículos.

A metodologia adotada para a investigação na indústria automobilística partiu do estudo original de Janssen (2000) e sofreu adaptações com os estudos de De Jong e Den Hartog (2010), dos quais se utilizou a qualificação das dimensões do comportamento inovador, conceito desenvolvido por esses estudiosos. Empregaram-se, como instrumento da pesquisa, os construtos "comportamento inovador na empresa", "liderança participativa", "associação do empregado com rede de contatos extrínseca ao ambiente de trabalho" e "efeito transformador".

Realizou-se uma revisão sistemática da literatura nas bases nacional e internacional Spell e World Scientific, respectivamente. Utilizaram-se os construtos "comportamento inovador" $\mathrm{e}$ innovative behavior nas palavras-chave e no resumo, sem limitação de período. Foram encontrados 4 (quatro) artigos na base nacional Spell, e, na base internacional 
World Scientific, pesquisada com o mesmo critério supracitado, encontraram-se 37 (trinta e sete) artigos.

A justificativa deste estudo, sob a ótica acadêmica, dá-se pelo fato de que ele trará contribuição para a academia tendo em vista que promove uma investigação acerca do comportamento inovador no setor industrial, apresentando novas análises para a literatura a respeito da temática, principalmente pelo fato de que, em âmbito nacional e internacional, há inexpressivos estudos sobre o comportamento inovador no ambiente automobilístico. Esta pesquisa de campo, baseada em estudo de caso, contribui, portanto, com a academia, considerando a necessidade de investigar e de desenvolver pesquisas no contexto brasileiro relacionada ao comportamento inovador e, efetivamente, instiga novas discussões sobre esse tema presente no ambiente competitivo das organizações.

Pela ótica pragmática, este estudo contribuirá com a empresa investigada, apontando elementos intrínsecos dos seus funcionários quanto à percepção das políticas motivadoras ao comportamento inovador, acerca da relação gestor e empregado. E esta pesquisa concentra-se em uma indústria automobilística, que inovará na academia contribuindo com novos enfoques acerca do construto.

\section{INOVAÇÃO}

As organizações, para se destacarem no mercado, utilizam a inovação como uma ferramenta de diferenciação. Para utilizar a inovação, necessita-se do sistema de informações e da tecnologia de comunicação e informação como uma ferramenta para administrar de forma mais assertiva a criação de estratégias (TVRDÍKOVÁ, 2013). A sociedade tornou-se mais exigente, buscando por melhores produtos e melhores serviços, e incentivou a concorrência entre os prestadores. Nesse sentido, a inovação contribui para o bom desempenho da organização, agregando valor ao seu produto e diferenciando-a dos concorrentes.

Essa nova exigência do mercado é tendenciosa, independentemente do setor de atuação da empresa e da área do empregado, uma vez que inovação é uma exigência para manter-se empregado ou no mercado, segundo Strobl et al. (2019) e Tenzer e Yang (2019), mesmo que, historicamente, determinada posição não exija um comportamento proativo e inovador (ABUKHAIT et al. 2019).

A inovação, de forma intrínseca, alavanca a lucratividade, cria alianças entre os stakeholders (influenciadores), majorando a valoração da companhia (SAMBIASE et al., 2013). Desenvolver-se por meio da inovação subentende invenção de novos produtos ou de novos serviços, mas pode-se inovar em processos já existentes, tornando-se mais eficaz ao realizar o mesmo serviço, porém de uma forma mais eficiente (TIDD; BESSANT, 2015).

Premissa da inovação é a fase da experimentação, em que o indivíduo desenvolve sua ideia, ou seja, coloca em prática seu projeto, buscando, por meio de ensaios com erros e acertos, a execução perfeita da sua proposta inicial (HASSI; REKONEN, 2018). Um exemplo são os processos de robotização, pelas indústrias, e Fintechs, pelo setor financeiro. Assim, as empresas precisam estimular a parte criativa de cada colaborador, como forma de persistência no mercado de trabalho (KHAOLA; COLDWELL, 2019).

A empresa necessita destacar-se da concorrência estimulando o funcionário a criar um diferencial e acrescentar valor aos produtos e serviços ofertados. A inovação permite à organização criar e desenvolver produtos, serviços a partir da ideação e implementação (AYUB; KAUSAR; QADRI, 2017; HASSI; REKONEN, 2018; TUOMINEN; TOIVONEN, 2011). Amabile (1988) e Kanter (1988) consideram como uma construção invenções a partir de elementos básicos da organização, remetendo à implementação 
desses ideais, como produtos, processos e serviços transformadores que acarretarão sucesso organizacional.

No entanto, muitas vezes, as empresas necessitam buscar conhecimento externo para desenvolvê-lo internamente, pois, devido à carência de recursos, não conseguem acessar informações mais avançadas. Dessa forma, esse conhecimento externo facilita seu desenvolvimento inovador internamente (MAJHI et al., 2020).

Portanto, uma empresa com clima inovador tende a disseminar esse comportamento entre os funcionários, pois os colaboradores com atitudes inovadoras são copiados pelos demais colegas de trabalho, o que os incentiva a ter o mesmo desempenho (KRUFT; GAMBER; KOCK, 2018).

$\mathrm{Na}$ literatura, há um entendimento acerca dos tipos de inovação: a incremental, em que se modifica a forma atual de realizar, produzir produto ou serviço, e a radical ou disruptiva, em que ocorre o rompimento do modo tradicional, criandose, por meio da tecnologia, um novo conceito, produto ou serviço, tornando-se o procedimento anterior antiquado (BOUNCKEN et al., 2017; ETTLIE; BRIDGES; O'KEEFE, 1984; KOBERG; DETIENNE; HEPPARD, 2003; RITALA; HURMELINNA-LAUKKANEN, 2012).

Assim, o comportamento do indivíduo é crucial para identificar a inovação a ser adotada pelas organizações. É considerado fundamental para implantações de pequenas inovações dentro da organização, iniciando-se pelas incrementais e, posteriormente, aprimorando-se para promover as disruptivas (DE JONG; KEMP, 2003).

\section{COMPORTAMENTO INOVADOR}

Ao se introduzir um projeto de inovação numa organização, torna-se necessário identificar na equipe de colaboradores o comportamento inovador. A característica do desempenho pode ser influenciada por vários fatores, como clima, liderança e perfil individual. Considera-se ainda o ambiente e o perfil dos colaboradores para a aderência do projeto tender ao sucesso e o desempenho. Sethibe e Steyn (2016), Ayub, Kausar e Qadri (2017) e Hasi e Rekone (2017) legitimam o perfil individual do colaborador e o perfil da liderança como fatores que influenciam o processo da organização.

Ayub, Kausar e Qadri (2017), Khalili (2016) e De Jong e Kemp (2003) entendem como comportamento inovador a ação direta dos indivíduos cujos benefícios correspondem a novas tecnologias e ideias que podem modificar os processos de forma mais eficiente e eficaz.

O comportamento inovador contribui para o ambiente, que proporciona a oportunidade para se reinventar; instiguese, portanto, o indivíduo a desenvolver a característica da criatividade. Kelysen e Street (2001) identificam comportamentos fundamentais no colaborador inovador: está sempre alerta para identificar as oportunidades, busca e reúne informações para reconhecer o momento da oportunidade de inovar.

Zhu, Djurjagina e Leker (2014) e Abukhait, Bani-Melhem e Zeffane (2019) acreditam que a criatividade se alinha ao comportamento inovador, assim como a proatividade é desejada pelos líderes. Em uma pesquisa realizada em uma multinacional de produtos químicos, Zhu, Djurjagina e Leker (2014) identificaram que a geração de ideias, em princípio, parte da criatividade de cada colaborador, porém a característica determinante para a aceitação dessa nova ideia por parte da empresa é a proatividade.

Amabile (1988) identifica os artefatos indispensáveis para o desenvolvimento da criatividade no indivíduo, sendo eles a capacidade complacente ao domínio da atividade e a capacidade inerente à motivação da tarefa. As características da evolução no processo de inventividade englobam a descrição acerca da individualidade e das capacidades 
psíquicas do indivíduo. Amabile (1988) e Hassi e Rekone (2017) destacam a resiliência no momento de insucesso e a ambição em imputar-se ao risco como fatores que contribuem para a criatividade.

O comportamento do indivíduo tende a ser influenciado pelas suas habilidades, e há uma positivação alinhada à criatividade, que Amabile (1988), Zhu, Djurjagina e Leker (2015) e Hassi e Rekone (2017) entendem ser o pilar do comportamento inovador. Ou seja, torna-se a propensão em elaboração de novos insights que inovam na perspectiva e nas práticas atuais.

Dessa forma, o comportamento inovador está diretamente conectado à criatividade de cada colaborador, mas, para desenvolvê-lo é necessário que algumas atitudes sejam incentivadas pela empresa (GAUDÊNCIO; COELHO; RIBEIRO, 2014). Entre elas, podem ser citadas: oportunidade de criar, elaborada em situações cotidianas que normalmente não são realizadas por padrões usuais; fomento de novas ideias, por meio de melhorias do processo atual; championing, objetivando esforços para impulsionar e implementar essas convicções, e aplicação, quando desenvolve e inclui na prática comercial da empresa essa inovação (DE JONG; KEMP, 2003; TUOMINEN; TOIVONEN, 2011).

Algumas empresas utilizam o crowdsourcing (compartilhamento de tarefas/pesquisas) como uma forma de impulsionar os funcionários para a geração de novas ideias e de mobilizar internamente todos os colaboradores para interagir e compartilhar suas ideologias e convicções. Assim, eles se motivam a partir de uma determinada ideia (ZHU; DJURJAGINA; LEKER, 2014).

A literatura identifica a autonomia dos empregados como uma forma assertiva de propiciar um ambiente adequado para estimular o comportamento inovador dos colaboradores. Acredita-se que o colaborador que faz suas atividades com independência tende a desenvolver um comportamento inovador mais arrojado
(SEO et al., 2015). O estímulo ao comportamento inovador do funcionário baseia-se no desafio enfrentado por ele ao realizar a atividade. É necessário que ele seja incentivado por meio dos fatores internos - quanto ao reconhecimento pela ideia e pelas ações desenvolvidas - e externos - quanto à parte financeira na folha salarial (AMABILE, 1988; DE JONG; KEMP, 2003). Nesse contexto, para que o colaborador desenvolva um comportamento inovador, torna-se necessário o desafio laboral, com seus estímulos intrínsecos e extrínsecos, além de um ambiente de autonomia para que ele possa desenvolver seus projetos inovadores de forma segura (DE JONG; KEMP, 2003).

$\mathrm{Na}$ academia, entende-se a inovação como primordial para as organizações se posicionarem competitivamente no mercado, logo a figura do líder destaca-se por desempenhar um papel importante quanto à inovação (SETHIBE; STEYN, 2016). Entende-se por liderança a capacidade de exercer uma interferência sobre outros indivíduos, voltando-se para um objetivo comum na organização (SETHIBE, 2017; SETHIBE; STEYN, 2016). O comportamento inovador recebe influência do estilo de liderança que a organização exerce: liderança transformacional e liderança transacional.

No que tange ao líder transacional, Oke, Munshi e Walumbwa (2009) e Sethibe e Steyn (2016) entendem dois fatores como marcantes: retribuição eventual e liderança contingencial. A primeira refere-se a uma compensação no momento em que os colaboradores respondem à expectativa da organização, e a segunda corresponde a um procedimento de liderança em que ocorre um efeito remediador.

As características fundamentais para o líder transformacional, segundo Oke, Munshi e Walumbwa (2009), envolvem quatro pilares, quais sejam, carisma, motivação, estímulo intelectual e consideração pormenorizada. Esse tipo de liderança permite ao colaborador ser estimulado de forma intrínseca, e os líderes 
são norteadores nos processos de mutação, desenvolvendo um clima e uma cultura organizacional equilibrados, convergindo para $\mathrm{o}$ fomento da mudança $\mathrm{e}$ do crescimento inovador.

Compreende-se como tendo estilo transformacional o líder cuja autoridade sobre o colaborador é exercida de forma convincente, ocasionando o aceleramento inovador do funcionário, o que reflete no desenvolvimento individual e coletivo. Oke, Munshi e Walumbwa (2009) e Sethibe e Steyn (2016) consideram o estilo de liderança transformacional eficiente e eficaz na propagação da criatividade no ambiente laboral. Já o estilo transacional enquadra-se no momento da implementação da novidade, sendo eficiente na inovação incremental. Assim, o estilo de liderança adequado impulsiona o desenvolvimento do indivíduo no que tange ao seu comportamento inovador.
Além da influência positiva na inovação, a liderança transformacional exerce influência positiva também no capital humano (SETHIBE, 2017). Segundo Ayub, Kausar e Qadri (2017), entende-se por capital humano a totalização da expertise dos indivíduos e sua capacidade de inovação e criatividade.

Isso posto, entende-se o comportamento inovador como um procedimento do indivíduo que se dá em diferentes etapas: identificar o obstáculo para fomentar ideias novas ou incrementais, desenvolver um pilar sustentador e criar uma matriz para utilização interna na organização (CARMELI; MEITAR; WEISBERG, 2006; KANTER, 1988; SETHIBE; STEYN, 2006; XERRI, 2014; XERRI; BRUNETTO, 2015).

Quanto ao comportamento inovador, o Quadro 1 mostra um resumo dos estudos feitos sobre esse tema, nacional e internacionalmente.

Quadro 1 - Resumo das pesquisas recentes acerca do comportamento inovador em âmbito nacional e internacional

\begin{tabular}{|c|c|c|c|}
\hline Temática do Artigo & Autores & Objeto de Análise & Resultados \\
\hline $\begin{array}{l}\text { Comportamento } \\
\text { inovador, bem-estar e } \\
\text { satisfação }\end{array}$ & $\begin{array}{l}\text { Xerri e Reid } \\
(2017)\end{array}$ & $\begin{array}{l}\text { Enfermeiros em } \\
\text { hospitais públicos } \\
\text { e privados }\end{array}$ & $\begin{array}{l}\text { O bem-estar, quando percebido pelo funcionário, intercede } \\
\text { o relacionamento entre a satisfação com oportunidades de } \\
\text { treinamento e o comportamento inovador. Também afeta a } \\
\text { satisfação do trabalho. }\end{array}$ \\
\hline $\begin{array}{l}\text { Comportamento } \\
\text { inovador, satisfação e } \\
\text { justiça organizacional }\end{array}$ & Xerri (2014) & Enfermeiros & $\begin{array}{l}\text { A relação da justiça processual e a satisfação no trabalho } \\
\text { da enfermagem são positivas e convergem para o } \\
\text { comportamento inovador, enquanto a justiça interativa } \\
\text { afeta a satisfação no trabalho. }\end{array}$ \\
\hline $\begin{array}{l}\text { Comportamento } \\
\text { inovador, tipos, } \\
\text { inovação e } \\
\text { conhecimento }\end{array}$ & $\begin{array}{l}\text { Tuominem e } \\
\text { Toivonen } \\
(2011)\end{array}$ & $\begin{array}{l}\text { KIBS: escritório } \\
\text { de arquitetura, } \\
\text { contabilidade e } \\
\text { consultoria de } \\
\text { engenharia }\end{array}$ & $\begin{array}{l}\text { Reconhecidas as dimensões do comportamento inovador, } \\
\text { identificaram-se diversos tipos de comportamentos } \\
\text { inovadores ao longo de um processo de inovação ou } \\
\text { mudança: a geração de ideias continua até o término do } \\
\text { processo e a aplicação inicia-se em seu estágio inicial. }\end{array}$ \\
\hline $\begin{array}{l}\text { Comportamento } \\
\text { inovador, ética } \\
\text { corporativa, } \\
\text { responsabilidade } \\
\text { social, } \\
\text { comprometimento } \\
\text { organizacional e } \\
\text { satisfação }\end{array}$ & $\begin{array}{l}\text { Gaudêncio, } \\
\text { Coelho e } \\
\text { Ribeiro } \\
(2014)\end{array}$ & $\begin{array}{l}\text { Empresa } \\
\text { portuguesa, } 43 \% \\
\text { serviços, } 36 \% \\
\text { indústria e } 18 \% \\
\text { comércio }\end{array}$ & $\begin{array}{l}\text { Os trabalhadores, ao se sentirem satisfeitos com a gestão, } \\
\text { tendem a valorizar a ética corporativa e a responsabilidade } \\
\text { social corporativa. E o comprometimento organizacional } \\
\text { influencia positivamente o comportamento inovador, } \\
\text { desenvolvendo-se uma performance laboral superior. }\end{array}$ \\
\hline $\begin{array}{l}\text { Comportamento } \\
\text { inovador, }\end{array}$ & $\begin{array}{l}\text { De Jong e } \\
\text { Kemp } \\
(2003)\end{array}$ & $\begin{array}{l}\text { Empresas de } \\
\text { serviços de } \\
\text { conhecimento }\end{array}$ & $\begin{array}{l}\text { A pesquisa relacionou empresas de serviços do } \\
\text { conhecimento, logo o ambiente de diferenciação favoreceu }\end{array}$ \\
\hline
\end{tabular}




\begin{tabular}{|c|c|c|c|}
\hline $\begin{array}{l}\text { determinantes e } \\
\text { inovação incremental }\end{array}$ & & & $\begin{array}{l}\text { o comportamento inovador. No entanto o clima de variação } \\
\text { elevada da demanda e apoio à inovação não influenciaram } \\
\text { de forma relevante tal comportamento, pois, nesse } \\
\text { segmento, a inovação incremental é vista com maior } \\
\text { impacto. }\end{array}$ \\
\hline $\begin{array}{l}\text { Comportamento } \\
\text { inovador, redes } \\
\text { sociais formais e } \\
\text { informais } \\
\text { (intercâmbio social) }\end{array}$ & $\begin{array}{l}\text { Brunetto et } \\
\text { al. }(2016)\end{array}$ & $\begin{array}{l}\text { Engenheiros, } \\
\text { gerentes e técnicos } \\
\text { (setor público e } \\
\text { privado) }\end{array}$ & $\begin{array}{l}\text { A relação de trabalho que apresenta uma abordagem } \\
\text { hierárquica diferenciada em que os empregados podem } \\
\text { utilizar-se como uma alternativa de beneficiar-se de } \\
\text { recursos e tornar-se proativos e inovadores, impactando o } \\
\text { comportamento inovador. }\end{array}$ \\
\hline $\begin{array}{l}\text { Comportamento } \\
\text { inovador, redes } \\
\text { sociais, capacidade de } \\
\text { subordinação, } \\
\text { sociabilidade e } \\
\text { cultura } \\
\text { organizacional } \\
\end{array}$ & \begin{tabular}{|l} 
Xerri e \\
Brunetto \\
$(2011)$
\end{tabular} & $\begin{array}{l}\text { Engenheiros e } \\
\text { gestores }\end{array}$ & $\begin{array}{l}\text { Verificou-se o impacto dos fatores capacidade de } \\
\text { subordinação, sociabilidade e cultura organizacional } \\
\text { acerca da criação de uma rede de relacionamento no local } \\
\text { de trabalho, com a finalidade da troca de experiência. }\end{array}$ \\
\hline $\begin{array}{l}\text { Comportamento } \\
\text { inovador, confiança e } \\
\text { compartilhamento de } \\
\text { conhecimento }\end{array}$ & $\begin{array}{l}\text { Seo, Kim, } \\
\text { Chang e } \\
\text { Kim (2015) }\end{array}$ & Personal trainers & $\begin{array}{l}\text { Identificou-se a relação de confiança entre os supervisores } \\
\text { e colaboradores como responsável pelo comportamento } \\
\text { inovador. }\end{array}$ \\
\hline $\begin{array}{l}\text { Comportamento } \\
\text { inovador, } \\
\text { empoderamento, } \\
\text { compartilhamento de } \\
\text { conhecimento e } \\
\text { gênero }\end{array}$ & $\begin{array}{l}\text { Abukhait, } \\
\text { Bani- } \\
\text { Melhem e } \\
\text { Zeffane } \\
(2019)\end{array}$ & Setor de serviços & $\begin{array}{l}\text { Esse estudo concluiu que os empregados empoderados } \\
\text { influenciam positivamente o comportamento inovador. }\end{array}$ \\
\hline $\begin{array}{l}\text { Comportamento } \\
\text { inovador e estilo de } \\
\text { liderança }\end{array}$ & $\begin{array}{l}\text { Sethibe e } \\
\text { Steyn } \\
(2016)\end{array}$ & $\begin{array}{l}\text { Empresas sul- } \\
\text { africanas }\end{array}$ & $\begin{array}{l}\text { O estudou identificou a relação positiva no comportamento } \\
\text { inovador dos estilos de liderança transformacional e } \\
\text { transacional. Notou-se que, entre os componentes dos } \\
\text { estilos de liderança, a estimulação intelectual, a motivação } \\
\text { inspiradora e a recompensa impactam positivamente o } \\
\text { comportamento inovador do colaborador. E há uma relação } \\
\text { contrária entre a influência idealizada e o comportamento } \\
\text { inovador. }\end{array}$ \\
\hline $\begin{array}{l}\text { Comportamento } \\
\text { inovador, inteligência } \\
\text { competitiva e } \\
\text { criatividade }\end{array}$ & $\begin{array}{l}\text { Khalili } \\
(2016)\end{array}$ & Indústrias & $\begin{array}{l}\text { Concluiu-se nesse estudo que os líderes que apresentam } \\
\text { inteligência emocional competitiva colaboram com os } \\
\text { funcionários no desenvolvimento de criatividade e } \\
\text { comportamento inovador dentro de suas empresas. }\end{array}$ \\
\hline $\begin{array}{l}\text { Comportamento } \\
\text { inovador, cultura } \\
\text { organizacional, redes } \\
\text { sociais e liderança }\end{array}$ & $\begin{array}{l}\text { Pugas et al. } \\
(2017)\end{array}$ & $\begin{array}{l}\text { Organização } \\
\text { varejista, } \\
\text { autointitulada } \\
\text { como inovadora }\end{array}$ & $\begin{array}{l}\text { Concluiu-se nesse estudo que os colaboradores } \\
\text { compreendem a necessidade da presença expressiva de } \\
\text { uma cultura organizacional, de liderança participativa e de } \\
\text { uma rede de relacionamento extrínseco para motivar o } \\
\text { comportamento inovador, porém a organização estudada } \\
\text { possui alto turn over, impedindo essa aderência ao } \\
\text { comportamento inovador. }\end{array}$ \\
\hline $\begin{array}{l}\text { Comportamento } \\
\text { inovador, } \\
\text { experimentação e } \\
\text { inovação }\end{array}$ & $\begin{array}{l}\text { Hassi e } \\
\text { Rekonen, } \\
(2018)\end{array}$ & $\begin{array}{l}\text { Instituição na } \\
\text { Finlândia }\end{array}$ & $\begin{array}{l}\text { Embora um indivíduo tenha os traços de personalidade e } \\
\text { estilos de pensamento que suportam o comportamento de } \\
\text { experimentação, isso não é suficiente para realizar } \\
\text { experimentos eficazes se não houver as habilidades de } \\
\text { experimentação requeridas e que serão desenvolvidas por } \\
\text { meio de feedback. }\end{array}$ \\
\hline
\end{tabular}




\begin{tabular}{|c|c|c|c|}
\hline $\begin{array}{l}\text { Comportamento } \\
\text { inovador, incubadora } \\
\text { corporativa e } \\
\text { inovação }\end{array}$ & $\begin{array}{l}\text { Kruft, } \\
\text { Gamber e } \\
\text { Kock }(2018)\end{array}$ & $\begin{array}{l}\text { Empresa de } \\
\text { hospedagem }\end{array}$ & $\begin{array}{l}\text { Incubadoras corporativas e clima de inovação afetam } \\
\text { significativamente o comportamento inovador do trabalho. }\end{array}$ \\
\hline $\begin{array}{l}\text { Comportamento } \\
\text { inovador, } \\
\text { personalidade e } \\
\text { carreira }\end{array}$ & $\begin{array}{l}\text { Abukhait, } \\
\text { Bani- } \\
\text { Melhem e } \\
\text { Shamsudin } \\
(2019) \\
\end{array}$ & $\begin{array}{l}\text { Setor hoteleiro de } \\
\text { Dubai }\end{array}$ & $\begin{array}{l}\text { A adaptabilidade à carreira mediou significativamente a } \\
\text { relação entre esses traços de personalidade e o } \\
\text { comportamento inovador. }\end{array}$ \\
\hline $\begin{array}{l}\text { Comportamento } \\
\text { inovador, gestão e } \\
\text { liderança }\end{array}$ & $\begin{array}{l}\text { Phil- } \\
\text { Thingvad et } \\
\text { al. (2019) }\end{array}$ & $\begin{array}{l}\text { Setor Público } \\
\text { Dinamarquês }\end{array}$ & $\begin{array}{l}\text { O conhecimento de estratégias de gestão (relatado pelo } \\
\text { gerente) e as percepções sobre comportamento gerencial } \\
\text { (relatadas pelos funcionários) afetam a percepção tida } \\
\text { pelos funcionários públicos quanto à geração, promoção e } \\
\text { realização de ideias. }\end{array}$ \\
\hline $\begin{array}{l}\text { Comportamento } \\
\text { inovador, liderança e } \\
\text { compromisso afetivo }\end{array}$ & $\begin{array}{l}\text { Khaola e } \\
\text { Coldwell } \\
(2019)\end{array}$ & $\begin{array}{l}\text { Organizações } \\
\text { públicas e } \\
\text { privadas de Lesoto }\end{array}$ & $\begin{array}{l}\text { O comprometimento afetivo modera a relação entre a } \\
\text { liderança apenas para uso pessoal, e o trabalho no } \\
\text { comportamento inovador, de modo que o relacionamento é } \\
\text { mais forte para funcionários comprometidos afetivamente, } \\
\text { enquanto é relativamente mais fraco para funcionários } \\
\text { menos comprometidos afetivamente. }\end{array}$ \\
\hline $\begin{array}{l}\text { Comportamento } \\
\text { inovador, liderança e } \\
\text { personalidade }\end{array}$ & $\begin{array}{l}\text { Strobl et al. } \\
(2019)\end{array}$ & $\begin{array}{l}\text { Executivo da } \\
\text { Áustria }\end{array}$ & $\begin{array}{l}\text { A humildade e a vontade profissional aumentam o } \\
\text { comportamento de inovação dos subordinados. }\end{array}$ \\
\hline $\begin{array}{l}\text { Comportamento } \\
\text { inovador, inovação e } \\
\text { ambidestria }\end{array}$ & $\begin{array}{l}\text { Majhi et al. } \\
(2020)\end{array}$ & $\begin{array}{l}\text { Indústria de } \\
\text { equipamento } \\
\text { Automotivo na } \\
\text { Índia }\end{array}$ & $\begin{array}{l}\text { Os papéis sinérgicos desempenhados na capacidade de } \\
\text { absorção individual e ambidestria individual para melhorar } \\
\text { a inovação comportamento dos gerentes operam em um } \\
\text { contexto aberto de inovação. }\end{array}$ \\
\hline
\end{tabular}

Fonte: Elaborado pelos autores.

A literatura exibe padrões de comportamento inovador no que tange ao tipo de mercado em que este está inserido, seja serviço, indústria ou outros. Nota-se uma oportunidade de comparar os resultados encontrados pelos autores com a base de dados no setor da indústria, em especial no setor automobilístico, ausente nessa revisão realizada e em que, ao longo dos anos de atuação no cenário brasileiro, diversas mudanças e tecnologias foram implementadas. Ressalta-se ainda a necessidade de buscar a percepção dos trabalhadores do setor diante da denominação aplicada por indústrias do segmento quanto a $4^{\text {a }}$ Revolução, em que os processos são intensivos em tecnologia e há um novo perfil de trabalhador e de consumidor (NOVIDA, 2020). É importante salientar que, nas pesquisas destacadas no Quadro 1, encontram-se metodologias qualitativas e quantitativas de investigação, sendo que o modelo de De
Jong e Den Hartog (2010) é mais utilizado em investigações quantitativas (GAUDÊNCIO; COELHO; RIBEIRO, 2014; KHALILI, 2016; BRUNETTO et al., 2016; HASSI; REKONEN, 2018; KHAOLA; COLDWELL, 2019), seguido pelo modelo de Scott e Bruce (1994) (CARMELI; MEITAR; WEISBERG, 2006).

Após a apresentação dos estudos realizados sobre o tema será apresentada, a seguir, a metodologia deste trabalho.

\section{METODOLOGIA}

Quanto aos fins, esta pesquisa caracteriza-se como descritiva, que, segundo Gil (2008), objetiva a delimitação de um determinado grupo ou a correlação entre fatores ou eventos. Os dados coletados do estudo traduzem as particularidades da empresa investigada, e a sua análise contribui para o estudo da relação entre 
gestor e empregado no que tange ao comportamento inovador. Quanto aos meios da pesquisa, trata-se de um estudo de caso, ou seja, uma investigação experimental que busca coletar informações mais incrementadas, com maior detalhe em apenas um objeto de análise, de forma que o pesquisador tenha evidências sustentáveis para relacioná-las com os construtos estabelecidos (GIL, 2008).

A indústria, situada no estado de Minas Gerais, possui 19.000 empregados. Para a coleta de dados, foram enviados emails a todos os funcionários da fábrica. $\mathrm{O}$ questionário foi enviado ao endereço eletrônico de trabalhadores das cinco fábricas e foi respondido através de um link da plataforma de administração de questionários SurveyMonkey. O envio ocorreu entre novembro de 2016 e maio de 2017, de forma aleatória, pois não foi possível identificar os setores e as áreas específicas dos trabalhadores que formaram a amostra. A pesquisa é classificada como não probabilística por conveniência, que Vergara (2014) entende ser a amostragem escolhida por permissividade e singularidade. Devido à localização da empresa, nesse caso, houve uma oportunidade na coleta de dados.

Utilizando a qualificação das dimensões do comportamento inovador desenvolvida pelos estudiosos De Jong e Den Hartog (2010), empregaram-se como instrumento da pesquisa os construtos "comportamento inovador na empresa", "liderança participativa", "associação do empregado com rede de contatos extrínseca ao ambiente de trabalho" e "efeito transformador". Dividiu-se o mecanismo de coleta em duas óticas, a do líder e a do subordinado. Os construtos "oportunidade", "geração de ideias", "championing" e "aplicação de inovação" foram examinados pelos líderes, enquanto, para os subordinados, utilizaram-se os construtos "suporte da liderança", "contatos externos" e "resultados de inovação", sendo essas as variáveis analisadas no estudo.

$\mathrm{O}$ estudo original investigou a percepção dos empregados por meio do trabalho desenvolvido por Janssen (2000), que realizou uma pesquisa acerca dos colaboradores e a teoria da troca social convergindo para o comportamento inovador. Quanto ao suporte à liderança e resultados de inovação foi desenvolvida uma escala relacionando-se seis itens e, quanto aos contatos externos, optou-se por uma de cinco itens. As escalas utilizadas para mensurar as respostas coletadas variam de 1 até 5 (nunca, raramente, às vezes, quase sempre, sempre, nessa ordem).

A técnica de análise de dados adotada nesta pesquisa foi a estatística descritiva univariada e bivariada, responsável por identificar as características do grupo estudado, suas diversidades e como os respondentes se classificam entre as variáveis estabelecidas pelo pesquisador (VERGARA, 2014). Adotou-se como teste de coeficiente de correção o spearman, sugerido pelas análises de De Jong e Den Hartog (2010).

$\mathrm{Na}$ Tabela 1, apresentam-se os questionamentos para os gestores como uma forma de avaliar as dimensões: comportamento inovador na empresa, desempenho da liderança e a correlação dos contatos externos e resultados inovadores, conforme o estudo de De Jong e Dan Hartog (2010). 
Quadro 2 - Questionário aos gestores

\begin{tabular}{|l|l|}
\hline \multicolumn{2}{|l|}{ Frases a serem consideradas } \\
\hline 1 & Prestam atenção a questões que não são parte de seu trabalho diário? \\
\hline 2 & Procuram oportunidades para melhorar as coisas? \\
\hline 3 & Consideram oportunidades inovadoras? \\
\hline 4 & Sabem como as coisas podem ser melhoradas? \\
\hline 5 & Exploram novos produtos ou serviços? \\
\hline 6 & Procuram novos métodos de trabalho, técnicas ou instrumentos? \\
\hline 7 & Geram soluções originais para problemas? \\
\hline 8 & Criam novas ideias? \\
\hline 9 & Encontram novas abordagens para executar tarefas? \\
\hline 10 & Mobilizam apoio para ideias inovadoras? \\
\hline 11 & Adquirem aprovação para ideias inovadoras? \\
\hline 12 & Fazem importantes membros da organização ficarem entusiasmados com ideias inovadoras? \\
\hline 13 & Tentam convencer as pessoas a apoiar uma ideia inovadora? \\
\hline 14 & Transformam ideias inovadoras em aplicações úteis? \\
\hline 15 & Introduzem sistematicamente ideias inovadoras em práticas de trabalho? \\
\hline 16 & Contribuem para a implementação de novas ideias? \\
\hline 17 & Colocam o esforço no desenvolvimento de coisas novas? \\
\hline
\end{tabular}
Fonte: Dados da pesquisa.

Após a aplicação dos questionários aos respondentes, inicia-se a análise acerca das dimensões identificadas conforme os questionamentos supracitados (Tabela 1).
Na primeira coluna, estão as dimensões estudadas; na segunda, a visão dos supervisores.

Tabela 1 - Resultados da análise de dimensões

\begin{tabular}{l|l} 
Dimensões & Supervisor \\
\hline Oportunidade & $1,2,3,4$ \\
\hline Geração de ideias & $5,6,7,8$ \\
\hline Championing & $9,10,11,12$ \\
\hline Aplicação & $13,14,15,16,17$ \\
\hline
\end{tabular}

Fonte: Dados da pesquisa.

No questionário respondido pelos supervisores, as respostas referentes às perguntas 1, 2, 3 e 4 dizem respeito à dimensão oportunidade. Referem-se à parte introdutória do procedimento para a inovação, que ocorre no momento de o agente demonstrar o comportamento inovador no ensejo de solucionar o problema ocorrido, gerando estímulos ao empregado para aperfeiçoar as circunstâncias atuais ou desenvolver uma solução ao prenúncio presente (DE JONG; DEN HARTOG, 2010).
A geração de ideias é averiguada nas respostas dos líderes às questões $5,6,7$ e 8 . Nota-se, segundo o modelo adotado, essa dimensão como uma forma de os empregados se mostrarem criativos ao deparar com problemas a serem solucionados, a inovar e apresentar seus projetos em um ambiente que os motive.
A dimensão
championing corresponde ao resultado das perguntas 9, 10, 11 e 12. Permitem ao supervisor identificar o colaborador que se depara com ambiente propício ao seu projeto, que 
colabora para o êxito de desenvolvimentos de suas conquistas inovadoras (DE JONG; DEN HARTOG, 2010).

$\mathrm{E}$, depois de apresentar insights inovadores, encontrar o ambiente propício que o motive, resta apenas a implementação, ou seja, a aplicação das inovações elaboradas e a apresentação dos resultados esperados, seja a inovação uma ruptura com o produto ou processo existente ou apenas incremental (DE JONG; DEN HARTOG, 2010). Essa dimensão foi analisada nas respostas das questões 13,14 , 15,16 e 17.

$\mathrm{Na}$ próxima seção, serão demonstrados os resultados e feita a análise a partir dos dados coletados na pesquisa.

\section{RESULTADOS}

Os dados da pesquisa realizada na empresa automobilística foram coletados por meio de uma SurveyMonkey direcionada para gestores e empregados. Os questionários recebidos foram 160 , sendo 28 de líderes e 132 de subordinados, o que, em conformidade com o número de respondentes, não descaracteriza a amostragem por tratar-se de uma pesquisa não probabilística. Os autores desta pesquisa adotaram o coeficiente alpha de Cronbach para avaliação de confiabilidade do questionário aplicado. Segundo Cronbach (1951), ao realizar uma pesquisa com o objetivo de mensurar algo, é importante atentar na exatidão e confiabilidade da sua medição, ou seja, o coeficiente alpha é um mecanismo responsável por mensurar o paralelismo da descrição demográfica dos respondentes e suas respostas formalizadas nos questionários (DA HORA; MONTEIRO; ARICA, 2010). Conforme estudos realizados pelos autores supracitados, para o coeficiente alpha ser considerado confiável, seu resultado deverá estar a partir de 0,70 . Nesta pesquisa, com relação à percepção dos gestores e dos empregados, o coeficiente de confiabilidade da pesquisa foi considerado "alto", com uma média de 0,965 .

Na Tabela 2, a seguir, mostra-se a percepção dos gestores em relação ao comportamento inovador presente na organização.

Tabela 2 - Percepção dos gestores quanto ao comportamento inovador na organização

\begin{tabular}{l|l|l|l|l} 
Dimensões do comportamento inovador & Média & DP & Mediana & Alpha \\
\hline Oportunidade & 3,63 & 0,37 & 3,50 & 0,921 \\
\hline Geração de ideias & 3,49 & 0,03 & 3,50 & 0,971 \\
\hline Championing & 3,44 & 0,07 & 3,50 & 0,955 \\
\hline Aplicação & 3,48 & 0,18 & 3,00 & 0,976 \\
\hline
\end{tabular}

Fonte: Dados da pesquisa.

Observa-se um número expressivo no que tange ao reconhecimento do gestor ao perceber o comportamento inovador nos seus colaboradores. Compreende-se, conforme a escala adotada, como "às vezes" todas as dimensões averiguadas, quais sejam, oportunidades, geração de ideias, championing e aplicação. Esse resultado corrobora os estudos realizados por Tuominen e Toivonen (2011), que aplicaram, por analogia, esse modelo no setor de serviços, usando o método qualitativo, em que as dimensões do comportamento inovador foram reconhecidas. Pode-se inferir, ao analisar os estudos relacionados ao comportamento inovador, a necessidade, por parte das empresas, de instigar nos empregados essa ousadia em explicitar suas ideias e compartilhar experiências, colaborando para superar adversidades pelas quais a organização possa estar passando.

Pela percepção dos empregados, as dimensões do comportamento inovador analisadas (Tabela 3), foram influenciadas pelos estudos realizados pelos autores Scott 
e Bruce (1994) e Janssen (2000). Adotaramse como influenciadores suporte da liderança, contatos externos e resultados de inovação.

Tabela 3 - Percepção dos empregados geral

\begin{tabular}{l|l|l|l|l} 
Dimensões & Média & DP & Mediana & Alpha \\
\hline Suporte da liderança & 2,95 & 0,15 & 3 & 0,988 \\
\hline Contatos externos & 2,47 & 0,29 & 2 & 0,978 \\
\hline Resultados de inovação & 3,11 & 0,63 & 3 & 0,968 \\
\hline
\end{tabular}

Fonte: Dados da pesquisa.

Compreende-se como suporte da liderança o apoio que os empregados recebem dos seus líderes para desenvolver suas habilidades e ideias inovadoras no ambiente de trabalho. Porém, identificou-se como "raramente" $(2,95)$ a frequência com que eles recebem esse apoio, o que se contrapõe às pesquisas realizadas por Scott e Bruce (1994), Janssen (2000), Sethibe e Steyn (2016) e Pugas et al. (2017), que concordam quanto à importância da liderança participativa no desenvolvimento do comportamento inovador da equipe na organização.

No que tange aos contatos externos, ou seja, networking - entendido como a rede social desenvolvida pelo profissional no decorrer da sua carreira -, não houve uma expressividade na concepção dos funcionários, sendo o item avaliado como "raramente" $(2,47)$, refutando os estudos de Xerri e Brunetto (2011), Brunetto et al. (2016), Puga et al. (2017) e Abukhait, BaniMelhem e Shamsudin (2019). Certifica-se a necessidade do desenvolvimento desses relacionamentos extrínsecos como uma forma de trocar experiências, beneficiando a organização quanto à solução de problemas, com baixo custo para ela, e, principalmente, como um estímulo para desenvolver o comportamento inovador entre os colaboradores. Dessa forma, a empresa tende a desenvolver uma equipe comprometida e engajada em promover o desenvolvimento a partir da inovação, além de compartilhar conhecimento tanto extrínseco quanto intrínseco à organização.

A dimensão resultados de inovação percebida pelos empregados foi avaliada como "às vezes" $(3,11)$, consequência da ausência de apoio de seus gestores, bem como do inexpressivo relacionamento extrínseco da equipe, o que afirma a importância da ligação entre essas dimensões, conforme os estudos supracitados.

Os estudos de De Jong e Den Hartog (2010) e de Pugas et al. (2017) afirmam que os fatores analisados são primordiais para induzir a inovação e criatividade no ambiente organizacional, pois envolvem as particularidades de cada colaborador ao solicitar sua opinião, recomendação, orientação e autonomia, envolvendo-os nas deliberações e na elaboração de novos conceitos ou serviços acerca dos produtos da empresa. A próxima análise (Tabela 4) corresponde à média da frequência dos respondentes sob a ótica dos funcionários no que tange ao suporte da liderança.

Tabela 4 - Média da percepção dos funcionários em referência ao suporte da liderança

\begin{tabular}{l|l|l|l|l}
\multirow{2}{*}{ Suporte da Liderança (questões) } & \multirow{2}{*}{ Média } & Frequência de Resposta por Níveis \\
\cline { 3 - 5 } & & Fraco & Médio & Forte \\
\hline Pede a minha opinião. & 3,03 & 24 & 29 & 26 \\
\hline Pede-me para sugerir como realizar tarefas. & 2,92 & 25 & 33 & 21 \\
\hline Consulta-me sobre mudanças importantes. & 2,85 & 29 & 27 & 22
\end{tabular}




\begin{tabular}{l|l|l|l|l}
$\begin{array}{l}\text { Deixa-me influenciar as decisões sobre os planos e direções } \\
\text { de longo prazo. }\end{array}$ & 2,7 & 30 & 28 & 21 \\
\hline Permite-me definir meus próprios objetivos. & 2,96 & 25 & 29 & 25 \\
\hline $\begin{array}{l}\text { Dá-me oportunidades consideráveis para a independência e } \\
\text { liberdade. }\end{array}$ & 3,2 & 23 & 22 & 34 \\
\hline
\end{tabular}

Fonte: Dados da pesquisa.

Nota-se que as questões "Dá-me oportunidades consideráveis para a independência e liberdade" e "pede minha opinião" aparecem como "às vezes", quantificadas como 3,2 e 3,03, respectivamente, corroborando as pesquisas anteriores de Seo et al. (2015), Pugas et al. (2017) e Abukhait, Bani-Melhem e Zeffane (2018), que concluíram haver necessidade de motivar os colaboradores e considerar suas ideias, promovendo um ambiente com autonomia, confiança e empoderamento. Assim, os colaboradores se sentirão confiantes para se posicionarem de forma inovadora na empresa.

Na visão dos colaboradores, o gestor "raramente" "permite definir meus próprios objetivos" e "permite realizar as tarefas de forma diferente que o usual", conforme apontou como 2,96 e 2,92, respectivamente, a média dos respondentes, o que mostra que falta autonomia para executar as atividades. Estudos referidos anteriormente apontam a importância da reversão dessas percepções pelos liderados. Scott e Bruce (1994) e Janssen (2000) entendem que os trabalhadores que possuem autonomia e têm confiança nos seus líderes tendem a contribuir com a inovação na empresa.

Apresentou-se como "raramente", na escala adotada pelos autores, a necessidade dos liderados em participar do processo de mudanças e decisões intrínsecas da organização, sendo a média de 2,85 e 2,7, respectivamente. Os líderes devem atentar na contribuição que os empregados podem dar à empresa, por meio de compartilhamento de seus conhecimentos trazidos de experiências laborais anteriores, pelas suas redes de contatos extrínsecos, ou seja, um colaborador motivado a desenvolver sua criatividade em um ambiente organizacional de confiança torna-se inovador e comprometido com a firma, o que é comprovado pelos estudos de Abukhait, Bani-Melhem e Zeffane (2018), Gaudêncio, Coelho e Ribeiro (2014), Seo et al. (2015) e Tuominen e Toivonen (2011).

$$
\text { Quanto à percepção dos }
$$
funcionários em relação às redes extrínsecas, a média dos resultados apresentados foi classificada como "raramente". Nota-se pouca influência dos relacionamentos externos, networking, no ambiente de trabalho (Tabela 5). Na revisão de estudos acadêmicos realizados pelos autores, constata-se a influência positiva que a rede social externa pode exercer na organização.

Tabela 5 - Média da percepção dos funcionários em referência às redes externas

\begin{tabular}{l|l|l|l|l}
\multirow{2}{*}{ Redes Externas (questões) } & \multirow{2}{*}{ Média } & \multicolumn{3}{l}{ Frequência de Resposta por Níveis } \\
\cline { 5 - 6 } & & Fraco & Médio & Forte \\
\hline $\begin{array}{l}\text { Mantém contato com potenciais clientes de minha } \\
\text { empresa. }\end{array}$ & 2,94 & 40 & 18 & 23 \\
\hline $\begin{array}{l}\text { Visita conferências, feiras e/ou exposições. } \\
\text { Fala com as pessoas de outras empresas em nosso } \\
\text { mercado. }\end{array}$ & 2,57 & 62 & 13 & 6 \\
\hline $\begin{array}{l}\text { Mantém contato com pessoas de instituições } \\
\text { universidades/conhecimento. }\end{array}$ & 2,66 & 43 & 21 & 24 \\
\hline
\end{tabular}

Fonte: Dados da pesquisa. 
Os funcionários têm pouco contato $(2,94)$ com os potenciais clientes da empresa e pouco intercâmbio social, quando se relaciona a visitas a feiras e/ou exposições $(2,57)$. Consoante os estudos de Xerri e Brunetto (2011), Brunetto et al. (2016) e Pugas et al. (2017), esse networking é satisfatório para o funcionário $\mathrm{e}$, principalmente, para a empresa, pois a troca de experiência e informação pode colaborar para a solução de problemas e ameaças iminentes, com baixo-custo de investimento. Além disso, os contatos nos eventos que ocorrem nas áreas de atuações podem contribuir com novas ideias, procedimentos, clientes e investidores.

Assim, sobre o desenvolvimento de parcerias com instituições universitárias e empresas do mesmo mercado, os respondentes apontaram como "raramente", sendo a média de 2,66 e 2, respectivamente. As inovações disruptivas e incrementais tendem a se desenvolver em uma organização aberta para o ambiente extrínseco, os contatos com outras empresas e universidades favorecem esse acontecimento, por meio do compartilhamento de conhecimento e da socialização, conforme constatam as pesquisas realizadas por Abukhait, BaniMelhem e Zeffane (2018), Brunetto et al. (2016), Seo et al. (2015) e Xerri e Brunetto (2011).

A última dimensão analisada pela percepção dos funcionários (Tabela 6) corresponde aos resultados da inovação, tendo uma ótica mais positiva, que elevou a média das respostas para "às vezes" e apenas um resultado classificado como "raramente". As práticas adotadas pelos funcionários com relevante resultado foram adquirir novos conhecimentos e produzir ideias para aperfeiçoar as práticas, sendo as médias, respectivamente, de 3,7 e 3,5, o que as correlacionam, uma vez que, ao desenvolver novos conhecimentos, com possibilidade de compartilhar experiências e aprimorar o konw-how, trazem para a organização, por meio de inferências, novas ideias e práticas para o desenvolvimento de inovações de serviços para o trabalho. Estudos já apontam para essas benfeitorias como os de Brunetto et al. (2016), De Jong e Kemp (2003), Gaudêncio, Coelho e Ribeiro (2014), Seo et al. (2015) e Xerri e Brunetto (2011).

Tabela 6 - Média da percepção dos funcionários em referência aos resultados de inovação

\begin{tabular}{|c|c|c|c|c|}
\hline \multirow{2}{*}{ Resultados de Inovação (questões) } & \multirow{2}{*}{ Média } & \multicolumn{3}{|c|}{$\begin{array}{l}\text { Frequência de Resposta por } \\
\text { Níveis }\end{array}$} \\
\hline & & Fraco & Médio & Forte \\
\hline Faz sugestões para melhorar os produtos ou serviços atuais? & 3,16 & 17 & 33 & 31 \\
\hline Produz ideias para melhorar as práticas de trabalho? & 3,5 & 12 & 28 & 41 \\
\hline Adquire novos conhecimentos? & 3,7 & 5 & 24 & 52 \\
\hline $\begin{array}{l}\text { Contribui ativamente para o desenvolvimento de novos produtos ou } \\
\text { serviços? }\end{array}$ & 3,2 & 24 & 30 & 27 \\
\hline Adquire novos grupos de clientes? & 2,1 & 55 & 15 & 11 \\
\hline
\end{tabular}

Fonte: Dados da pesquisa.

O colaborador comprometido com a organização importa-se em participar do aperfeiçoamento de serviços e produtos e pontua sua ideia para aperfeiçoá-lo. Essas considerações foram classificadas na pesquisa como "às vezes" 3,2 e 3,16 , nessa ordem. A pesquisa apresentou um desenvolvimento ao integrar a presença do colaborador nos processos decisórios. É importante dar-lhe essa confiança para que ele possa desenvolver a criatividade, tornando-se um profissional autônomo e com comportamento inovador. Dessa forma, criará uma responsabilidade social com ética corporativa, pois suas opiniões serão ouvidas, discutidas e recompensadas 
(ABUKHAIT; ZEFFANE, 2018; GAUDÊNCIO;

BANI-MELHEM; COELHO; RIBEIRO, 2014; SEO et al., 2015; SETHIBE; STEYN, 2016).

Entende-se essa pontuação pouco significativa para os resultados inovadores, qualificada como "raramente" $(2,1)$ na percepção dos funcionários, por ser pouco expressiva a rede social dos funcionários, sendo que esse networking favorece a captação de clientes, conforme classificação já aludida. A organização é responsável por estimular o intercâmbio social entre os funcionários e externamente, o que é uma forma de captar novos grupos de clientes, conforme atestam os estudos sobre essa variável (ABUKHAIT; BANIMELHEM; $\quad$ ZEFFANE, 2018; BRUNETTO et al., 2016; PUGAS et al., 2017; XERRI; BRUNETTO, 2011).

Isso posto, a próxima seção trará as considerações finais deste estudo.

\section{Considerações finais}

Este trabalho apresentou a seguinte questão como pergunta norteadora: Como são percebidas, por gestores $e$ colaboradores, as características do comportamento inovador dentro de uma indústria do setor automobilístico situada no estado de Minas Gerais? Como base para solucionar essa interpelação, utilizouse uma pesquisa descritiva e realizou-se um estudo de caso em uma indústria automobilística em Minas Gerais, em que se ouviram gestores e subordinados, num total de 132 respondentes, por meio de uma SurveyMonkey, no período de novembro de 2016 e maio de 2017. Como instrumento para mensurar a avaliação dos gestores, utilizaram-se os estudos de De Jong e Den Hartog (2010), e, para mensurar a percepção dos empregados, os estudos de Scott e Bruce (1994) e Janssen (2000).

Em relação à percepção dos gestores quanto às dimensões analisadas, observouse comportamento inovador nos liderados, que apresentou um número expressivo quantificado na escala adotada como "às vezes". Isso corrobora os resultados encontrados pelos autores anteriormente mencionados, pressupondo a necessidade atual de a empresa investir nos processos de inovação, permitindo e estimulando seus funcionários a explicitar suas ideias e contribuições, convergindo para um comportamento inovador, como um meio de a organização manter-se em destaque e liderança em seu segmento.

Quanto à percepção dos empregados, a análise dos resultados auferidos identificou a motivação dos gestores em desenvolver o comportamento inovador como pouco expressivo. Pode-se inferir a carência do gestor em expor a real necessidade da empresa em inovar e integrar o funcionário com as estratégias a serem definidas pela diretoria. Dessa forma, ele criará um comprometimento organizacional, ofertando aos colaboradores uma liberdade em expor suas ideias e compartilhar o conhecimento adquirido tanto extrínseco quanto intrínseco à organização.

A partir da análise dos resultados, pode-se concluir que a organização analisada apresentou uma diferença da percepção dos gestores e subordinados. Sob a ótica dos gestores, há uma preocupação em desenvolver um comportamento inovador nos funcionários e instigá-los a isso, porém percebe-se que os subordinados não compreendem explicitamente esse incentivo por parte dos líderes. Conforme os estudos acerca do comportamento inovador, é necessário que haja uma simetria entre ambos, convergindo para as necessidades da empresa. Atualmente, com a disseminação da internet e a inovação nos serviços e produtos ocorrendo a todo vapor, os colaboradores deverão apresentar um comportamento inovador explícito, aparente, e os gestores devem identificar tal comportamento em seus subordinados e instigá-los a se expressarem. Para tanto, os gestores devem adotar uma gestão mais próxima, de forma a envolver todos os interessados nas etapas de melhoria e aperfeiçoamento dentro da empresa, para 
que esta possa manter-se numa posição sustentável na cadeia produtiva. Essa divergência de percepção apontada neste estudo pode indicar uma nova lacuna para estudos futuros.

As pesquisas apresentadas pelos autores encontrados nas análises realizadas nas bases Spell e World Scientific, corroboram os resultados encontrados no presente estudo. Pode-se inferir que as organizações necessitam envolver todos os colaboradores, sendo os gestores os responsáveis por disseminar esse envolvimento de todos no desenvolvimento do comportamento inovador dentro da empresa. Conforme os resultados apurados pelos autores desta pesquisa, sugerem-se algumas práticas para desenvolver esse desempenho nos subordinados. Como exemplo, o intercâmbio social com o objetivo de trocar boas práticas e aprimorar novas ideias intrínseca e extrinsecamente, convergindo para o desenvolvimento inovador da organização, uma vez que, conforme Ayub, Kausar e Quadri (2017), Rekonen (2018) e Tuominen e Toivonen (2011), a empresa necessita destacar-se da concorrência, estimulando o funcionário a criar um diferencial e desenvolver produtos e serviços ofertados.

No que tange às implicações acadêmicas, este estudo torna-se importante por apresentar diferentes percepções dos gestores e colaboradores sobre a motivação do comportamento inovador dentro da organização. Os resultados contribuirão com a academia, uma vez que a pesquisa realizou-se em um segmento diferente dos já analisados, qual seja, uma indústria automobilística e, mesmo assim, seus resultados encontram-se em consonância com os apontados no Quadro 1.

Logo, entende-se a importância de investigar e de desenvolver pesquisas relacionadas ao comportamento inovador de forma constante. Trata-se de uma possível maneira de mensurar, de forma detalhada, essas divergências de percepções, por meio de uma análise longitudinal, assim o pesquisador poderá acompanhar as fases pelas quais os funcionários e a organização estejam passando, tais como do período dos estímulos às ideias inovadoras, da implementação até a efetivação, e isso ainda poderia demonstrar a distinção ou a relação entre a percepção de gestores e funcionários.

É primordial que a organização se prepare para uma nova fase, vanguardista, de gerenciar, adaptando-se às novas tendências de mercado e às influências recebidas, de modo externo, por meio de produtos e serviços oferecidos por startups, universidades e fornecedores, e, de modo interno, pela rede dos próprios empregados. Além disso, as organizações deverão identificar, por meio de uma análise, as ações mais adequadas para o perfil de seu segmento a fim de amenizar as divergências de percepções dos gestores e empregados.

A pesquisa realizada tem limitações, a primeira das quais, o fato de que a pesquisa foi aplicada em apenas uma empresa do setor industrial, não se obtendo dados comparativos de setores diversos ou do mesmo setor, porém de outra região. A segunda limitação diz respeito à ausência dos dados demográficos, o que dificultou diferenciar as percepções com relação a gênero, idade, sexo e faixa salarial. Como terceira limitação, aponta-se o número dos respondentes, que limitou a pesquisa, não possibilitando uma margem mais robusta de resultados. A quarta limitação está no fato de que, por se tratar de uma pesquisa quantitativa, os dados mensurados tornamse absolutos, não permitindo inferências sobre influências do ambiente e circunstanciais nos respondentes.

Como sugestão de futuros estudos, sugerem-se caminhos que busquem mensurar como o impacto do comportamento inovador pode desnudar relevantes questões, tanto teóricas quanto gerenciais para as organizações, visto que muito se investe em inovação, porém os efeitos reais para a organização ainda se configuram como gap. Entender a interação com a cultura organização e valores pode 
contribuir com a percepção sobre variáveis que se relacionam com o comportamento inovador. Também indica-se a realização de pesquisas, concomitantemente, quantitativa e qualitativa, mensurando o comportamento inovador, prevalecendo os mesmos instrumentos e ampliando os respondentes. Dessa forma, a abordagem qualitativa propiciará identificar o real sentimento dos entrevistados, além de levantar os dados demográficos, utilizando-se desse recurso para avaliar as influências no comportamento inovador de elementos como idade, gênero, sexo. E, por fim, sugere-se uma comparação com outras empresas de diferentes setores e a realização de um estudo com a mesma empresa em suas filiais localizadas em outros estados e países.

\section{REFERÊNCIAS}

ABUKHAIT, Rawan Mazen; BANIMELHEM, Shaker; ZEFFANE, Rachid. Empowerment, knowledge sharing and innovative behaviours: exploring gender differences. International Journal of Innovation Management, v. 23, n. 1, p. 1950006, 2018.

ABUKHAIT, Rawan; BANI-MELHEM, Shaker; SHAMSUDIN, Faridahwati Mohd. Do employee resilience, focus on opportunity, and work-related curiosity predict innovative work behaviour? the mediating role of career adaptability. International Journal of Innovation Management, v. 24, n. 1, p. 2050070, 2019.

AMABILE, Teresa M. A model of creativity and innovation in organizations. Research in organizational behavior, v. 10, n. 1, p. 123-167, 1988.

AYUB, Umer; KAUSAR, Abdul Rashid; QADRI, Mubashar Majeed. Linking Human Capital and Organisational Innovative Capabilities of Financial Institutions: Evidence from a Developing
Country of South Asia. Journal of Information \& Knowledge

Management, v. 16, n. 4, p. 1750042, 2017.

BOUNCKEN, Ricarda B. et al. Coopetition in new product development alliances: advantages and tensions for incremental and radical innovation. British

Journal of Management, v. 29, n. 3, p. 391-410, 2018.

BRUNETTO, Yvonne et al. The role of informal and formal networks: how professionals can be innovative in a constrained fiscal environment. International Journal of Innovation Management, v. 20, n. 3, p. $1650051,2016$.

CARMELI, Abraham; MEITAR, Ravit; WEISBERG, Jacob. Self-leadership skills and innovative behavior at work. International Journal of Manpower, v. 27, n. 1, p. 75-90, 2006.

CLAPHAM, Maria M. The development of innovative ideas through creativity training. In: The international handbook on innovation. 2003. p. 366-376.

CRONBACH, Lee J. Coefficient alpha and the internal structure of tests. Psychometrika, v. 16, n. 3, p. 297334, 1951.

DA HORA, Henrique Rego Monteiro; MONTEIRO, Gina Torres Rego; ARICA, José. Confiabilidade em questionários para qualidade: um estudo com o Coeficiente Alfa de Cronbach. Produto \& Produção, v. 11, n. 2, p. 85-103, 2010.

DAN, Xin et al. Innovative behaviour and career success: Mediating roles of selfefficacy and colleague solidarity of nurses. International Journal of Nursing Sciences, v. 5, n. 3, p. 275-280, 2018. 
DE JONG, Jeroen; KEMP, Ron.

Determinants of co-workers' innovative behaviour: An investigation into knowledge intensive services. International Journal of Innovation Management, v. 7, n. 2, p. 189-212, 2003.

DE JONG, Jeroen; DEN HARTOG, Deanne. Measuring innovative work behaviour. Creativity and innovation management, v. 19, n. 1, p. 23-36, 2010.

ETTLIE, John E.; BRIDGES, William P.; O'KEEFE, Robert D. Organization strategy and structural differences for radical versus incremental innovation. Management Science, v. 30, n. 6, p. 682-695, 1984.

GAUDÊNCIO, Pedro; COELHO, Arnaldo; RIBEIRO, Neuza. Organisational CSR practices: employees'perceptions and impact on individual performance. International Journal of Innovation Management, v. 18, n. 4, p. 1450025, 2014.

HASSI, Lotta; REKONEN, Satu. How individual characteristics promote experimentation in innovation. International Journal of Innovation Management, v. 22, n. 04, p. 1850038, 2018.

JANSSEN, Onne. Job demands, perceptions of effort-reward fairness and innovative work behaviour. Journal of Occupational and Organizational Psychology, v. 73, n. 3, p. 287-302, 2000.

KHALILI, Ashkan. Linking Leaders'emotional Intelligence Competencies And Employees'creative Performance And Innovative Behaviour: Evidence From Different Nations. International Journal of Innovation Management, v. 20, n. 7, p. 1650069, 2016.
KHAOLA, Peter; COLDWELL, David. 'Please Lead Me, My Commitment Is Low': Interactive Effects Of Commitment And Leadership On Innovative Behaviour. International Journal of Innovation Management, v. 23, n. 2, p. 1950015 , 2019.

KANTER, Rosabeth Moss. Three tiers for innovation research. Communication Research, v. 15, n. 5, p. 509-523, 1988.

KOBERG, Christine S.; DETIENNE, Dawn R.; HEPPARD, Kurt A. An empirical test of environmental, organizational, and process factors affecting incremental and radical innovation. The Journal of High Technology Management Research, $v$. 14, n. 1, p. 21-45, 2003.

KRUFT, Tobias; GAMBER, Michael; KOCK, Alexander. Substitutes or complements? The role of corporate incubator support and innovation climate for innovative behavior in the hosting firm. International Journal of Innovation Management, v. 22, n. 5, p. 1840006 , 2018.

MAJHI, Siddharth Gaurav et al. The energistic role of individual absorptive capacity and individual ambidexterity in open innovation: a moderated-mediation model. International Journal of Innovation Management, p. 2050083, 2020 .

NOVIDA. Indústria Automobilística: tendências e inovações. Disponível em: https://www.novida.com.br/blog/industriaautomobilistica. Acesso em: 23 jun. 2020.

OKE, Adegoke; MUNSHI, Natasha; WALUMBWA, Fred O. The influence of leadership on innovation processes and activities. Organizational Dynamics, v. 38, n. 1, p. 64-72, 2009. 
PHIL-THINGVAD, Signe; KLAUSEN, Kurt Klaudi. Managing The Implementation Of Innovation Strategies In Public Service Organisation-How Managers May Support Employees Innovative Work Behaviour. International Journal of Innovation Management, p. 2050074, 2019.

PUGASA, Maurício Alves Rodrigues et al. Mensuração da relação entre o comportamento inovador, contatos externos, liderança participativa e resultados inovadores: um estudo exploratório por meio de equações estruturais. Revista de Administração, Contabilidade e Economia da Fundace, v. 8, n. 2, 2017.

PRAJOGO, Daniel I.; AHMED, Pervaiz K. Relationships between innovation stimulus, innovation capacity, and innovation performance. R\&D

Management, v. 36, n. 5, p. 499-515, 2006.

RITALA, Paavo; HURMELINNALAUKKANEN, Pia. Incremental and radical innovation in coopetition-The role of absorptive capacity and appropriability. Journal of Product Innovation Management, v. 30, n. 1, p. 154-169, 2013.

SAMBIASE, Marta Fabiano; FRANKLIN, Marcos Antonio; TEIXEIRA, Jaqueline Alfim. Inovação para o desenvolvimento sustentável como fator de competitividade para as organizações: um estudo de caso Duratex. RAI-Revista de Administração e Inovação, v. 10, n. 2, p. 144-168, 2013.

SEO, Hyo Min et al. Influence of Interpersonal Trust on Innovative Behaviour of Service Workers: Mediating Effects of Knowledge

Sharing. International Journal of Innovation Management, v. 20, n. 2, p. 1650026, 2016.
SETHIBE, Tebogo Gilbert. Towards a comprehensive model on the relationship between leadership styles, organisational climate, innovation and organisational performance. International Journal of Innovation Management, v. 22, n. 2, p. $1850021,2018$.

SETHIBE, Tebogo; STEYN, Renier. The impact of leadership styles and the components of leadership styles on innovative behaviour. International Journal of Innovation Management, v. 21, n. 2, p. 1750015, 2017.

SCOTT, Susanne G.; BRUCE, Reginald A. Determinants of innovative behavior: A path model of individual innovation in the workplace. Academy of Management Journal, v. 37, n. 3, p. 580-607, 1994.

STROBL, Andreas et al. Triggering subordinate innovation behavior: the influence of leaders'dark personality traits and level 5 leadership behavior. International Journal of Innovation Management, v. 23, n. 5, p. 1950045, 2019.

TUOMINEN, Tiina; TOIVONEN, Marja. Studying innovation and change activities in KIBS through the lens of innovative behaviour. International Journal of Innovation Management, v. 15, n. 2, p. 393-422, 2011.

TIDD, Joe; BESSANT, Joe. Gestão da inovação-5. Porto Alegre: Bookman, 2015.

TVRDÍKOVÁ, Milena. Increase in the competitiveness of SMEs using business intelligence in the Czech-Polish border areas. In: Computer Science and Information Systems (FedCSIS), 2013 Federated Conference on. IEEE, 2013. p. 981-984.

VAIDYAA, Saurabh; AMBADB, Prashant; BHOSLEC, Santosh. Industry 
4.0-a glimpse. Design Engineering, v. 2351, p. 9789, 2018.

VERGARA, Sylvia Constant. Projetos e relatórios de pesquisa em administração.

São Paulo: Atlas. 2014.

XERRI, Matthew J. Examining the relationship between organisational justice, job satisfaction and the innovative behaviour of nursing employees. International Journal of Innovation Management, v. 18, n. 1, p. 1450004, 2014.

XERRI, Matthew J.; BRUNETTO, Yvonne. The impact of the perceived usefulness of workplace social networks upon the innovative behaviour of SME employees: A social capital perspective. International Journal of Innovation Management, v. 15, n. 5, p. 959-987, 2011.

XERRI, Matthew J.; REID, Stuart RM. Human Resources And Innovative Behaviour: Improving Nursing Performance. International Journal of Innovation Management, v. 22, n. 02, p. $1850019,2018$.

ZHU, Hangzi; DJURJAGINA, Katharina; LEKER, Jens. Innovative behaviour types and their influence on individual crowdsourcing performances. International Journal of Innovation Management, v. 18, n. 6, p. $1440015,2014$.

\section{${ }^{i}$ Cristiana Fernandes De Muylder}

Full Professor at FUMEC University. PhD in Applied Economics, Master in Rural Economics, Specialist in Strategic Planning and Information Systems, Bachelor of Computer Science.

\section{ii Liliane Andrade Araújo}

Master's degree in Business from FUMEC University. Specialist in Financial Administration FGV and Bachelor of Law.

\section{iii Jefferson Lopes La Falce}

$\mathrm{PhD}$ in Business from FUMEC University, Master in Business University Center Unihorizontes, Specialist in Strategic Marketing Management from UFMG and Bachelor of Business Administration from PUCMinas.

\section{iv Sander Rosa de Laia Mesquita}

Master's degree in Business from FUMEC University. Specialist in Strategic Management in Logistics from PUCMinas, Bachelor of Administration from PUCMinas 